
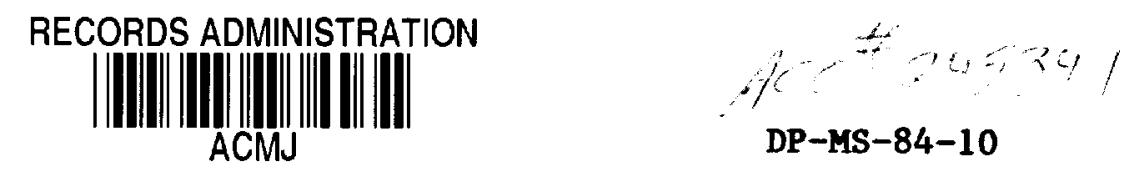

CARBON DIOXIDE EXCHANGE AND GROWTH OF A PINE PLANTATION

by

Charles E. Murphy, Jr.

E. I. du Pont de Nemours \& Co.

Savannah River Laboratory

Aiken, South Carolina 29808

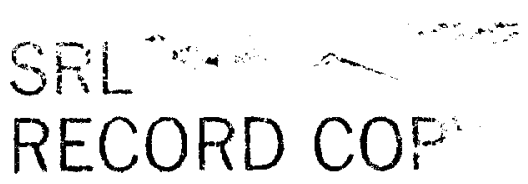

A paper proposed for publication in

Forest Ecology and Management

This paper was prepared in connection with work done under Contract No. DE-AC09-76SR00001 with the U.S. Department of Energy. By acceptance of this paper, the publisher and/or recipient acknowledges the U.S. Government's right to retain a nonexclusive, royalty-free license in and to any copyright covering this paper, along with the right to reproduce and to authorize others to reproduce all or part of the copyrighted paper. 
DP-MS-84-10

\section{CARBON DIOXIDE EXCHANGE AND GROWTH OF A PINE PLANTATION*}

by

Charles E. Murphy, Jr.

E. I. du Pont de Nemours \& Co.

Savannah River Laboratory

Aiken, South Carolina 29808

\section{Abstract}

The exchange of materials between the atmosphere and terrestrial ecosystems is important to an understanding of the cycling of essential elements, the deposition of materials from the atmosphere and the entrance of pollutants into the forest ecosystems. This paper reports the results of measurements of carbon dioxide exchange in a vigorously growing pine plantation. Measurement data were incorporated into a model used to estimate annual carbon dioxide exchange and measured annual biomass accumulation in the same plantation were used to determine a carbon dioxide to biomass conversion efficiency. Carbon dioxide exchange was 10.5 metric tons per hectare and biomass accumulation was 4.5 metric tons per hectare. The conversion efficiency of carbon dioxide to biomass is about $25 \%$ less than the theoretical chemical conversion efficiency. Considering the possible errors in both of the estimates, this is very good agreement.

The information contained in this article was developed during the course of work under Contract No. DE-AC09-76SR00001 with the U.S. Department of Energy. 


\section{Introduction}

An increase in the atmospheric carbon dioxide concentration has been observed over the last two decades (Keeling et al.1976). A few older measurements indicate this trend may have been taking place over centuries (Woodwell et al. 1978). The ocean is the most significant reservoir of carbon dioxide. The turnover of the deep ocean is very slow and the carbon contained in terrestrial ecosystems is large enough to be significant in the global carbon balance over periods of decades or centuries. However, it is not certain whether there is a net positive or negative carbon flux between the atmosphere and terrestrial ecosystems. This has led to an increased interest in the rate of carbon accumulation in terrestrial ecosystems and particularly in forest ecosystems. The measurement of carbon accumulation in forests is a new facet of a problem that has been the central focus of much of forest science for a long time, the understanding of the growth and development of forest stands.

The objective of the research reported in this paper was to measure the carbon dioxide exchange of a vigorously growing forest that was rapidly accumulating carbon. The measurements were used to estimate the annual carbon accumulation of the forest. The estimated carbon accumulation was compared to biomass accumulation as a check on the consistency of the estimates. It was expected that the carbon accumulation rate (growth) of this temperate forest ecosystem would be comparatively high, providing an estimate in the upper range of carbon accumulation by these ecosystems. 


\section{Methods}

Measurement of Carbon Dioxide Flux Density

The "combination" or "modified Bowen ratio" (Bowen 1926) technique was used to measure the flux density of water vapor, heat and carbon dioxide between the forest and the atmosphere. Measurements were made through the summer and fall of 1980. The first measurement data were taken June 2, and the last on November 7. Measurement periods varied from only eight daylight hours to continuous measurements for over 60 hours. Measurements were made on fifteen separate days.

The Bowen ratio technique requires that there by only vertical transport of the material or energy of interest and that the vegetation and aerodynamic boundary layer above the sand be homogeneous in every direction around the measurement area. The technique is based on measurement of the forest energy balance and the profiles of temperature, water vapor density, and carbon dioxide concentration measured at a number of heights above the forest.

The forest energy balance is described by the equation,

$$
a S+L-R=R_{n}=1 E+C+G+S_{t}+P_{n}
$$

The net radiation $\left(R_{n}\right)$ absorbed by the forest is the sum of the absorbed solar radiation (aS), the incident terrestrial or long-wave radiation ( $L$ ) and the long-wave reradiation ( $R$ ). The net radiation is partitioned between the latent heat of vaporization of water (1E), the sensible heat transfer (C), the heat transfer to the ground beneath the forest (G), the change in heat storage to the stand $\left(S_{t}\right)$ and the net metabolic storage $\left(P_{n}\right)$. In practice the metabolic energy transport 
and the heat storage in the vegetation are not significant and are ignored in calculations.

The Bowen ratio is defined as the ratio of the sensible heat transfer to the latent heat transfer. Using the flux-gradient form of the transfer equations, this leads to:

$$
B=c / 1 E=\frac{r{ }_{p} K \frac{d T}{d z}}{1 K \frac{d v}{d z}}=\frac{r c_{p}}{1} \frac{d T}{d v}
$$

In this equation the density of air $(r)$, the specific heat of air $\left(c_{p}\right)$ and the latent heat of vaporization (1) are simple functions of air temperature and humidity. The gradient of potential temperature ( $T$ ) and water vapor density $(v)$ with height $(z)$ are measured. The main advantages of the Bowen ratio technique are twofold. First, the diffusivities ( $K$ ) for heat and water vapor need not be evaluated, but only assumed to be equal. Additionally, the gradients of potential temperature and water vapor density with height need not be evaluated directly, but only the change in potential temperature with water vapor density, which is normally constant in the boundary layer above the forest, is needed. Figure 1 shows a plot of potential temperature against water vapor density for a typical daylight period. The derivative $\mathrm{dT} / \mathrm{dv}$ in Equation (2) is estimated as the slope of the line defined by this plot. The flux densities of sensible and latent heat can be found from the Bowen ratio and the net radiation from the equations

$$
\begin{aligned}
& C=\left(R_{n}-G\right) /(1+B) \\
& 1 E=\left[\left(R_{n}-G\right) B\right] /(1+B)
\end{aligned}
$$




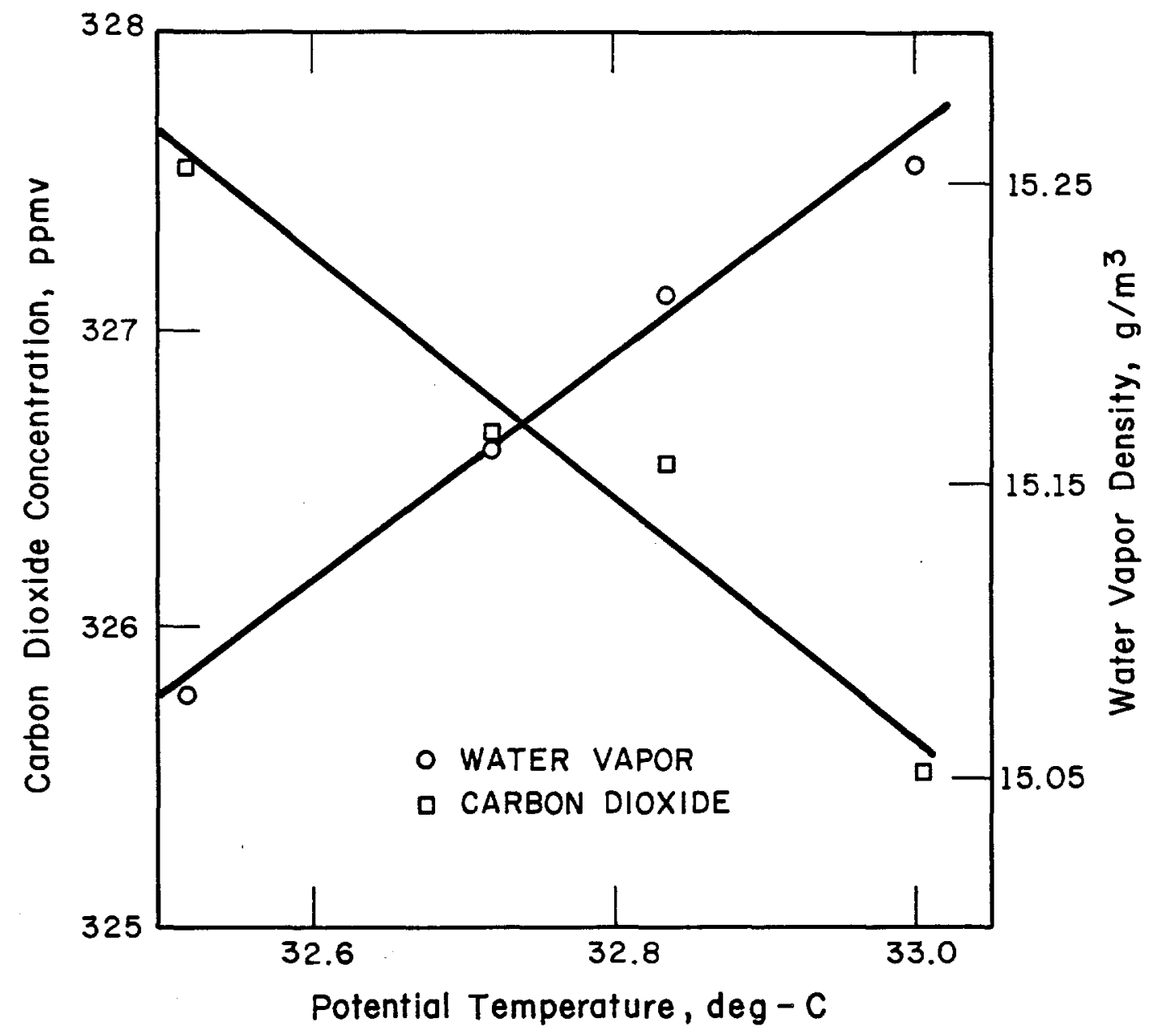


An extensive of the Bowen ratio can be used to determine flux densities (F) of other materials when a profile can be measured. A new ratio $\left(R_{c}\right)$ is defined which is the ratio of the flux density of the material of interest, in this case carbon dioxide $\left(F_{c}, C_{c}\right)$, and the net radiation minus the ground heat transfer. The defining equation is :

$$
\begin{aligned}
R_{c} & =\frac{F_{c}}{R_{n}-G}=\frac{F_{c}}{1 E+C}=\frac{K \frac{d C_{c}}{d z}}{R\left(1 \frac{d v}{d z}+r c_{p} \frac{d T}{d z}\right.} \\
& =\frac{1}{r c_{p}} \frac{\frac{d c_{c}}{d T}}{1.0+(1.0 / B)]}
\end{aligned}
$$

A number of authors have pointed out sources of error in the Bowen ratio calculations as they are given above (Warhaft 1976, Webb et al. 1980). The errors are caused by correlations in humidity and temperature in the air density requiring the existence of a very small vertical velocity (Webb et al. 1980). The flux densities calculated in this paper were corrected using the method of (Webb et al. 1980). The correction was significant at times decreasing the calculated carbon dioxide flux by as much as a third.

\section{Nocturnal Measurements of Flux Densities}

Bowen ratio estimates of flux densities should be reliable at any time other than periods of near zero latent heat exchange when the Bowen ratio approaches infinity. However, at night the boundary layer above the stand becomes very shallow, as turbulent mixing is suppressed by increasing thermal stability of the atmosphere. During this period 
the upper measurement levels for temperature, water vapor density and carbon dioxide concentration may not reflect the heat and water vapor transfer of the forest beneath the measurement site. Under these conditions it may possible to calculate flux densities by using the time derivatives of temperature, water vapor density and carbon dioxide instead of the spatial derivatives normally used (Droppo 1978).

$$
R_{c}=\frac{F_{c}}{R_{n}-G}=\frac{K \frac{d c_{c}}{d t}}{k\left(1 \frac{d v}{d t}+r c_{p} \frac{d T}{d t}\right)}
$$

In this case the forest is not assumed to be at a quasi-steady state as it is when spatial derivatives are used, but in a slowly changing transient condition. The same assumption of similarity of the processes transferring sensible heat, latent heat, and carbon dioxide are assumed. However, at night, turbulent transfer, the mode of transfer assumed to be similar for all the fluxes, appears to break down under very stable atmospheric conditions. Transfer appears to take place intermittently during periods of "turnover" which are not fully understood. However, periods do occur when the criterion for use of Equation (5) are met.

\section{Ground Heat Transfer}

A sensitivity analysis (Sinclair et al. 1975) of the Bowen ratio equation indicates that, during midday conditions, the ground heat flux density can be ignored in Bowen ratio calculations. However, during the night, the ground $c$ an be a significant source of heat to the atmosphere above the forest. For this reason, an effort was made to measure the flux density of heat exchanged with the ground ( $v a n$ Wijk and de Vries 1966). The thermal diffusivity of the surface soil was 
calculated by measuring the temperature at four depths and computing the amplitude and the phase angle of the diurnal and shorter wavelength temperature cycle using Fourier analysis. The damping depth(D) for each of the harmonics of different angular frequency (w) was determined by fitting a semi-logarithmic plot of amplitude versus depth. The thermal conductivity $\left(k_{s}\right)$ of the surface soil was calculated from the diffusivity $\left(k_{s}\right)$ and the soil heat capacity $\left(c_{v}\right)$.

$$
\mathrm{k}_{\mathrm{s}}=\mathrm{c}_{\mathrm{v}} \mathrm{k}_{\mathrm{s}}=\mathrm{D}^{2} \quad \mathrm{w} \mathrm{c}_{\mathrm{v}} / 2
$$

The heat capacity was calculated on the basis of the dry soil bulk density and the moisture content taken with a gamma density gage. The soil heat flux density used in the Bowen ratio calculations was calculated as the product of the conductivity and the temperature gradient between the shallowest two depths measured.

\section{Calculation of Transport Resistances}

The resistance analogue model of gas exchange between the atmosphere and the surface of the earth has proven useful as both a diagnostic and predictive tool (Penman 1948, Monteith 1965, and Thom 1975). One form of this model treats the vegetated surface as a single "big leaf" to calculate transfers of heat and water vapor (Monteith 1965). This model has been modified to include transport of other gaseous pollutants (Sinclair et al. 1976, Hicks and Wesely 1980). The resistances in the path of heat and water vapor transport are an aerodynamic resistance to heat and water vapor transport and an additional canopy resistance to water vapor transport from inside the vegetation. 
The aerodynamic resistance to momentum transport can be calculated from precise measurement of the wind speed (u) profile at different heights above the forest. The wind speed observations are statistically fit to the equation:

$u=u_{*} k\left[\ln \left\langle(z-d) / z_{0}\right\rangle-f\langle(z-d) / L\rangle\right]$

The parameters used to fit the equation to the data are the friction velocity $\left(u_{*}\right)$, the displacement height (d) and the roughness length $\left(z_{0}\right)$. The value of von Karman's constant $(k)$ is about 0.35 . The profile correction for convective heat transfer $[f(z / L)]$ is a function of the height above the displacement height $(z-d)$ and the Monin-Obukov length. The Monin-Obukov length is defined by the equation:

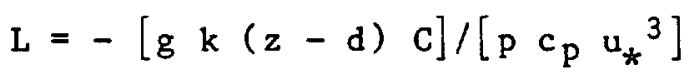

where $g$ is the acceleration of gravity, $C$ the flux density of sensible heating of the atmosphere, $p$ the density of air, and $c_{p}$ the specific heat of air. The relationships developed (Businger 1971, Lettau 1979, and Paulson 1970) were used to calculate the convective profile correction.

The aerodynamic resistance to momentum transport is equal to the wind speed at the height of interest divided by the friction velocity squared $\left(u / u_{\star}{ }^{2}\right)$. The aerodynamic resistance for momentum is not equal to the aerodynamic resistance to heat of water vapor transport because of the existence of form drag for momentum transport which has no counterpart in heat or water vapor transport. The effect of form drag has been estimated to be proportional to the inverse of the friction velocity, where the proportionality constant is about $0.1 \mathrm{~m} / \mathrm{sec}$. This leads to the equation (Thom 1975): 


$$
r_{a}=\left(u / u_{*}^{2}\right)+\left(a / u_{*}\right)
$$

Once the value of the aerodynamic resistance is determined, the canopy resistance can be calculated by the equation (Monteith 1965, Stewart and Thom 1973):

$$
r_{c}=\left[(d l b) /\left(r c_{p}\right)-1\right] r_{a}+(B+1) r_{i}
$$

Where $d$ is the derivative of saturation vapor density with respect to temperature and the climatological resistance $\left(r_{i}\right)$ is defined as:

$$
r_{i}=\frac{v_{s}-v}{I\left(R_{n}-G\right)}
$$

The saturation vapor pressure $\left(v_{s}\right)$ is a function of temperature of the air. The canpopy resistance is approximately equal to the product of the integrated resistance to water vapor diffusion over the stoma on the needle surface and the leaf area per unit surface area of the forest.

\section{Instrumentation}

A 1 ist of the instruments used in the experiments is provided in Appendix A. Measurements of temperature and air samples were taken at heights of $8.86,9.84,11.36$, and 13.47 meters from a 13.5 meter tower located at the center of the pine plantation. Temperature was measured as temperature differences between two heights with five junction, copper-constantan thermopiles. The lowest level was referenced to an ice bath. Wind speeds were measured at $8.17,9.35,10.67,11.81$, and 12.90 meters with sensitive cup anemometers. 
Soil temperatures were measured at two locations, one near the base of a tree and the other in an open area between the tree crowns. Two junction thermopiles, referenced to an ice bath, were set at depths of $2.5,5.1,12.7$, and 25 centimeters below the soil surface.

Net radiation was measured with a polyehtylene domed radiometer having upward and downward measuring faces. This provided a measure of the difference between the downward and upward radiation flux density. Two net radiometers were suspended two meters above the top of the canopy. A quartz-domed solarimeter was used to measure the radiation in the short-wave part of the spectrum.

Air samples were pumped to a distribution system constructed of five separate pumps pushing air, under positive pressure through an array of solenoid actuated valves. The distribution system included a 19-1iter mixing vessel for each air line and allowed air sampled from each sampling height to be fed sequentially through a pressure transducer, a dewpoint hygrometer and an infrared carbon dioxide analyzer. The infrared gas analyzer was used in a differential mode for measurement of carbon dioxide differences between levels. Span and zero were checked against standard gases at the beginning of each measurement period. The dewpoint measurements were corrected for pressure differences between sample 1 ines and the carbon dioxide measurements were corrected for pressure and water vapor content differences.

The data acquisition was controlled by a microcomputer calculator system. Analog signals were brought into the system through a scanner which selected the signal to be measured under calculator control. The 
signal from the scanner was digitized by a digital multimeter and transferred to the calculator. Air temperature, soil temperature, solar radiation, and net radiation were scanned as fast as the system could cycle between sensors and accumulated for 30 minute averaging periods.

The solenoid valves in the air distribution system were controlled through a relay actuator. Air from a selected level was allowed to flow through the pressure transducer, and split between the dewpoint analyzer and the infrared carbon dioxide analyzer. The sequence of measurement between levels took one minute. First the analyzers were given a chance to equilibrate with the air for thirty seconds after the valve was opened. Then measurements were taken at the selected level for the remaining thirty seconds as part of the measurement cycle of all the transducers. All measurements for a particular level were averaged to provide a thirty-minute average for computations.

At the end of a thirty-minute measurement period, the average values were output to a nine track magnetic tape for further analysis. The data was analyzed in the calculator to provide output of key parameters to check for instrumental problems. The raw data was also printed out on the calculator printer to provide a backup copy in case of magnetic tape problems.

\section{Measurement of Biomass Accumulation}

The measurements were made at the same site as the carbon dioxide exchange experiments. The twelve-year-old loblolly pine, Pinus taeda, $\underline{\text { L. }}$ plantation was located at 81 degrees, 40 minutes west 1 ongitude, and 
33 degrees, 21 minutes north latitude, near the town of New Ellenton, South Carolina. The site is in the upper Atlantic coastal plain province in the Aiken plateau subprovince. The area is characterized by gently rolling hills eroded by numerous drainage tributaries. The soils are well drained, consisting of sands, of varying depths, overlying less permeable clay subsoils. At the experimental site the surface soil layer is about one meter of sand overlaying a heavy clay which impedes drainage during the winter. The clay also appears to impede root penetration, limiting rooting depth to the surface layer. Biomass measurements were taken on two plots using a stratified sampling scheme. Diameter at breast height (DBH) and height aboveground (HT) was measured on each tree in the sample plots during the winters of the measurement year and the following year. The trees were grouped by $\mathrm{DBH}$ in $2 \mathrm{~cm}$ interval classes. One tree was selected from each DBH class, and the diameter at the base of each branch and the number of growing tips on each branch were measured. Thirty-six trees, six in each diameter class, were chosen randomly on each tree, and the diameter at the base of the branch and the number of branch tips measured. At intervals during the year, a tree was selected from each diameter class and the sample branches removed. Branch and needle weight of each branch were measured and a regression between the basal area of each branch, the number of tips, and mass was developed. This regression was used to estimate tree branch mass and needle mass for the intensively measured sample trees. With this estimate of individual tree masses, a regression was developed to estimate tree needle and 
branch mass for individual trees from tree diameter and height. The form of this equation is :

$$
M=b\left(\mathrm{DBH}^{2} \mathrm{HT}\right)
$$

where $b$ is the fitting constant and $M$ is the mass of the component of interest. The total needle mass and total branch mass was estimated for the standby using the regression on the $D B H$ and height for the trees in the sample plots.

The mass of the tree stems was estimated from the height and $D B H$ data from regressions developed for loblolly for a slightly younger stand of trees (Nemeth 1972) and from regressions developed for a slightly older stand of trees (Ralston 1974). The agreement between the two estimates is better than ten percent. Nemeth's regression was used in making estimates because the tree heights and DBH's spanned the range found in the plantation being studied. The regression equation used by Nemeth was of the form:

$$
\begin{aligned}
\ln M & =a_{0}+a_{1} \ln (D B H+1)+a_{2}[\ln (D B H+1)]^{2} \\
& +a_{3}[\ln (H T)]^{2}
\end{aligned}
$$

No measurements were made of the mass of the below-ground components of the tree. Nemeth 1972, estimated that the below-ground mass of a slightly younger loblolly pine plantation was about $20 \%$ of the total stand mass. Ralston 1974, reports measurements of a slightly older plantation indicate the below-ground mass was $16 \%$ of the total mass. Nemeth's estimate was used in determining the mass and growth of the plantation studied here. 
Needle area. index is needed to estimate the surface area for carbon dioxide exchange in the stand. The needle area was calculated from leaf weight from a relationship developed from a subsample of needles. The needle area was determined for surfaces by measuring the length of a string wrapped around a needle in four places equally spaced along the needle and multiplying the average circumference by the needle length. The leaf area index for each measurement made during the year are presented in Table 1.

\section{Results}

Daylight Heat, Water Vapor, and Carbon Dioxide Flux Density

Figure 2 shows the trends of the thirty-minute average air temperature, air water vapor density, and carbon dioxide concentration over a typical two-day period beginning in the afternoon of July 1, 1980. The most obvious characteristics of this series of data is the increasing temperature during the daylight hours and the increasing carbon dioxide concentration during the night. Vapor density also appears to increase during the day, although the day-to-day trend dominates the variation over the period. These characteristics are easily explained by the fact that the source of heat and water vapor is in the forest during the day, while the forest is a sink for carbon dioxide during the same period. At night the forest becomes a source of carbon dioxide and is often a sink for water vapor or heat.

The thirty-minute flux densities of the energy balance components and the carbon dioxide flux density were calculated for the daylight periods using Equations (2), (3), (5), and (6). In addition, the flux 
densities are calculated for the entire 24 hours of the day for the two day period beginning on July 1, 1980. Figure 3 shows the solar radiation, net radiation, and soil heat flux densities for the July 1 period. The soil heat flux densities were calculated from the temperature differences between the 2.5 and $5.0 \mathrm{~cm}$ depth thermopiles. Analysis of six periods indicated a damping depth of $18.5 \mathrm{~cm}$. Because of the 1 ack of rain during the measurement period the soil moisture did not change greatly during five of the periods. The damping depth, moisture content, and calculated heat capacity for each period with sufficient data for calculations are shown in Table 2 .

Figure 4 shows the heat and latent heat (water vapor) flux densities for the period during July 1-3, 1980. Figure 5 shows the carbon dioxide flux density for the same period. This period is typical of the rest of the data. The energy balance flux densities from the middle of the morning until dark appear to have reasonable values. During the night, the calculated flux densities jumped from positive to negative values of about the same size. Furthermore, there are periods when the magnitude of the flux densities are completely unrealistic.

These results are probably caused by a combination of the shallowness of the nocturnal boundary layer relative to the measurement points and the fact that the nocturnal boundary layer is intermittently "turned over" by instabilities of unknown origin. The profiles of air temperature versus water vapor density are very chaotic during the night. This condition continues into the early morning. In the 


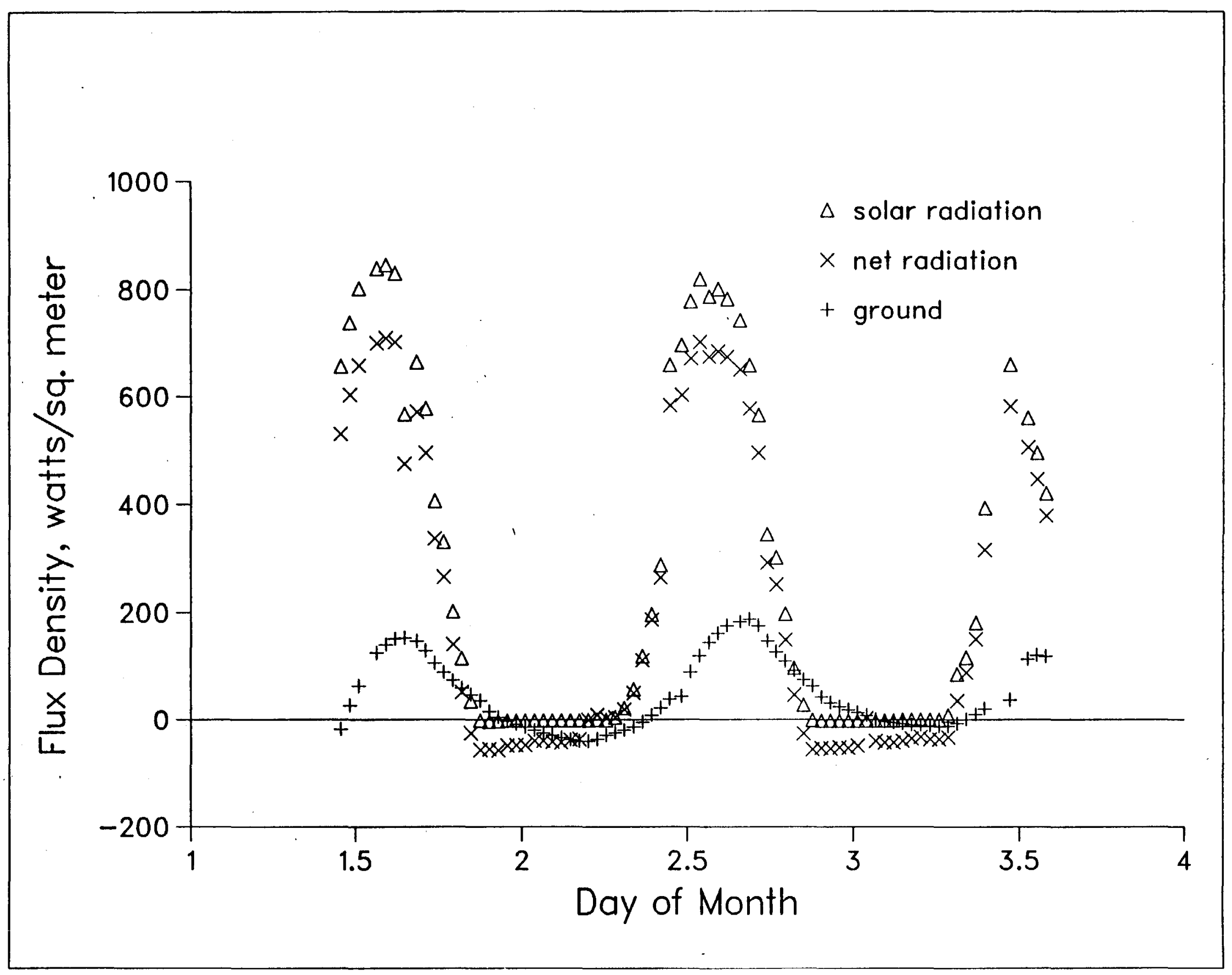




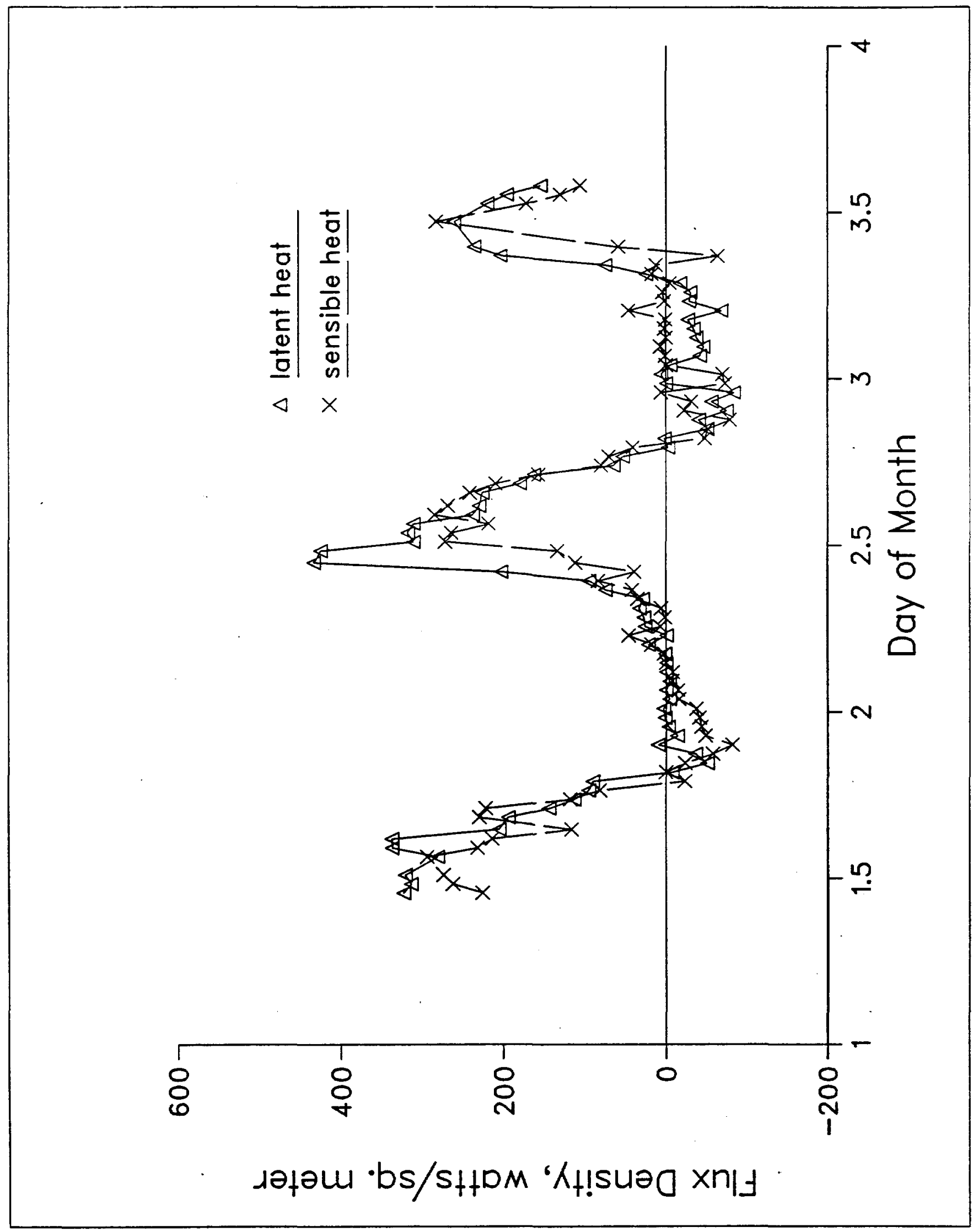




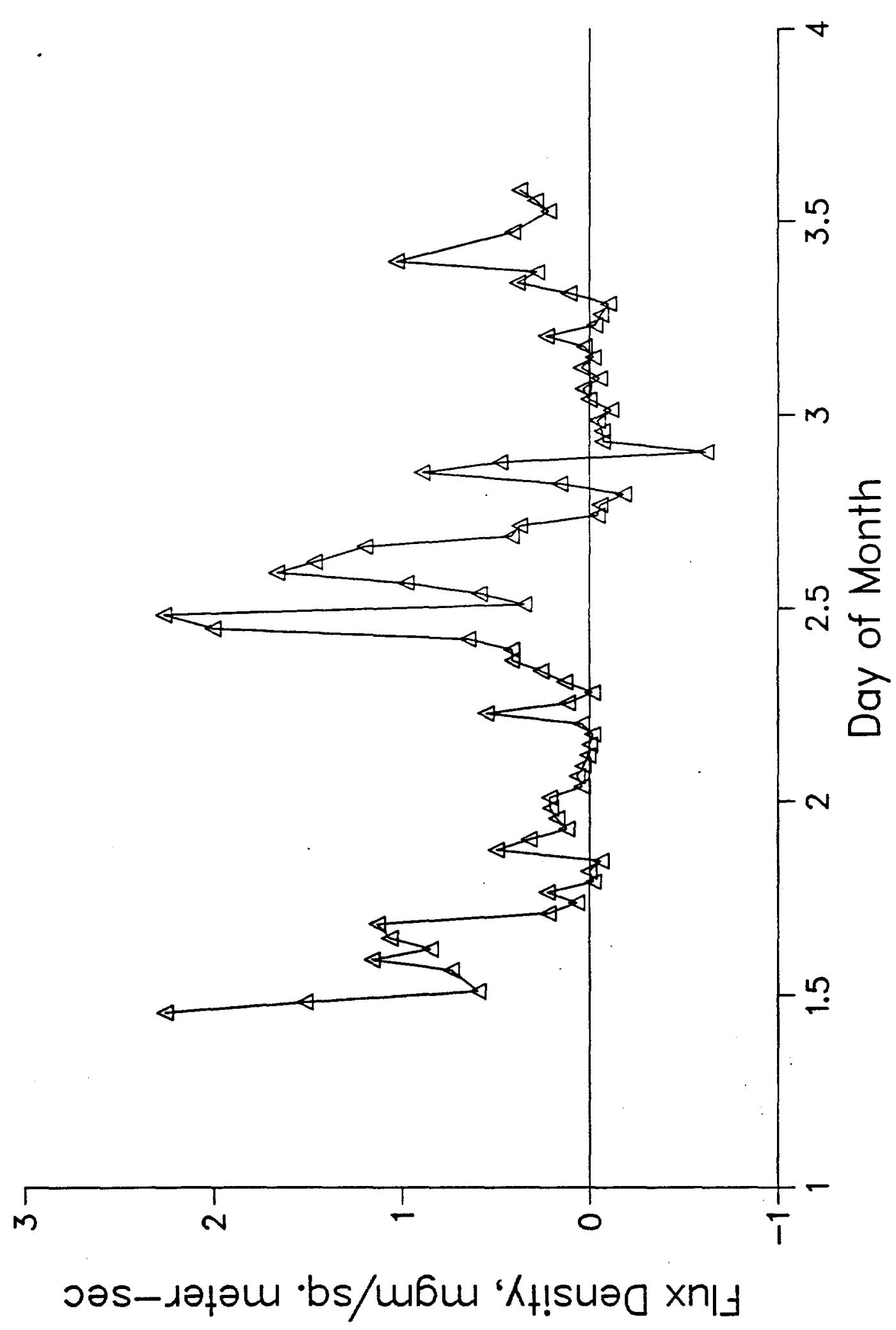


later part of the morning, the three lower measurement points form a linear profile and finally, before noon all five points fall on a single straight line. The linear profile normally persists until just before sunset when the chaotic pattern may form very suddenly.

In the early morning it appears that the boundary layer is still quite shallow from the previous night. However, if the potential temperature, water vapor density, and carbon dioxide concentration of the two levels closest to the canopy are used to calculate the flux densities; the values of the flux densities are of the right size and follow the trends evident for other values calculated on the same day. In any case, the profile measurements are not able to predict flux densities for the nocturnal periods.

\section{Nocturnal Carbon Dioxide Flux Densities}

Because of the difficulty of estimating nocturnal flux densities with the profiles, an alternative method was tried. The time derivative of temperature with respect to vapor density and carbon dioxide with respect to temperture were evaluated for nocturnal periods having the following characteristics: 1) the changes in the magnitude of the three parameters were large enough to measure, 2) the slopes were linear, and 3 ) the net radiation and ground heat flux densities were not changing rapidly. The flux density of carbon dioxide was calculated using Equations (4) and (5). The results are shown, plotted against temperature, in Figure 6. 


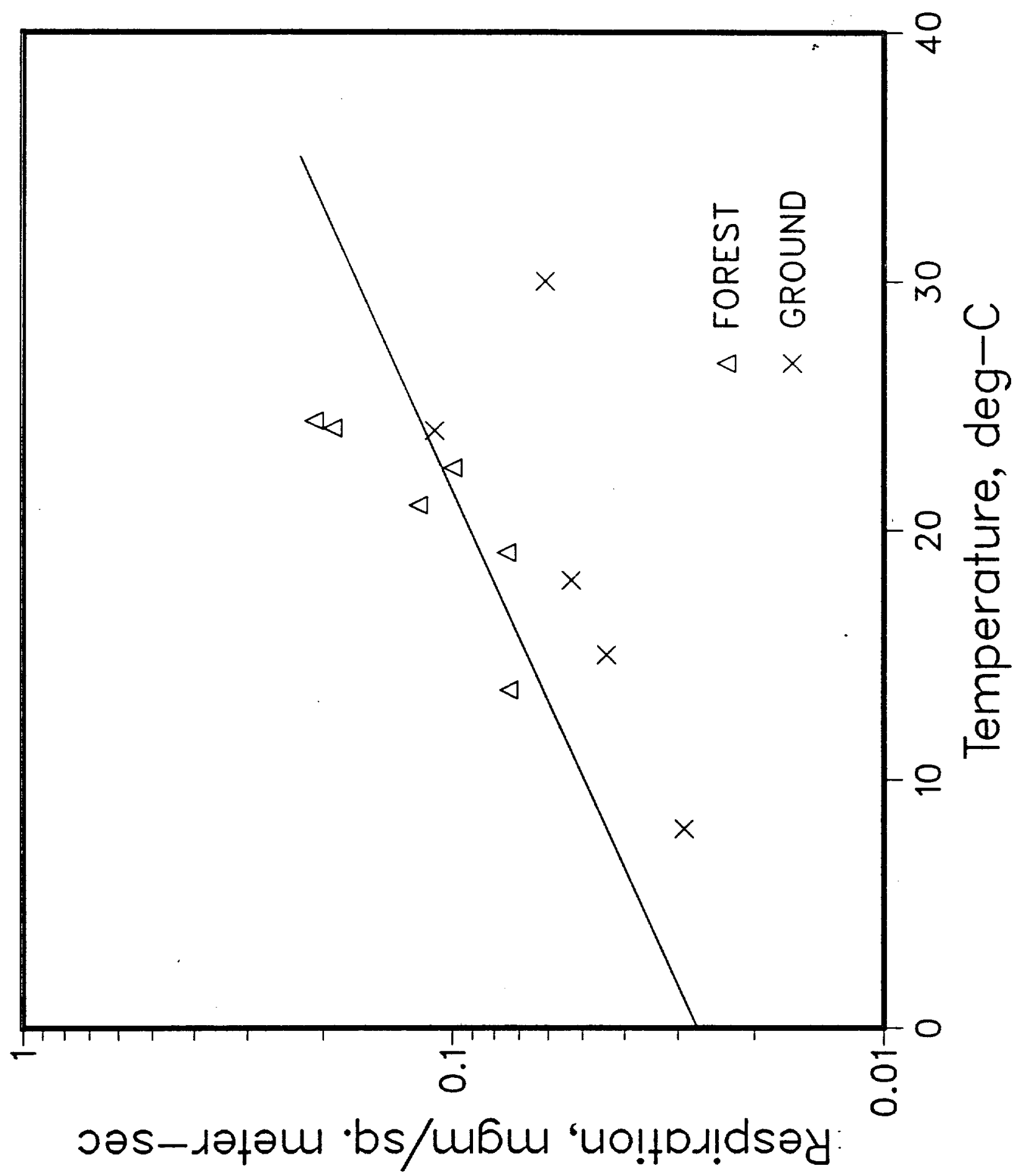


The nocturnal carbon dioxide flux density is the result of two processes: respiration of the forest vegetation and respiration of soil microorganisms. Practically, the respiration flux density is usually partitioned into respiration from aboveground and below-ground portions of the forest. The below-ground respiration, measured as efflux at the soil surface, is both microbial and root respiration. Figure 6 also shows the magnitude of the soil carbon dioxide flux under a similar loblolly pine plantation (C. W. Sweet, personal communication). The variability in these data can be explained as response to temperature and soil water content. The $Q_{10}$, the fractional increase in respiration with a $10^{\circ} \mathrm{C}$ change in temperature, of the soil carbon dioxide flux density appears to be close to two. The $Q_{10}$ of the nocturnal flux densities of the entire forest appears to be between two and three. The magnitude of the fluxes and the $Q_{10}$ are similar to those reported elsewhere (Kinerson 1975).

The nocturnal flux densities of heat and water vapor have not been calculated for these periods. Even though the values could be calculated for the periods used in the carbon dioxide calculations it is unlikely that these periods are typical of nocturnal heat and water vapor transport. Nocturnal heat and water vapor transport are often limited by turbulent transfer. The periods used in these calculations were chosen for turbulent transfer characteristics that are probably not typical nocturnal conditions. Typical nocturnal conditions include many periods of "turnover" and rapid fluctuations of the parameters used in the calculations. The carbon dioxide flux density is not 
controlled by the transport in the atmosphere but by the respiration rate of the forest organisms. Thus the carbon dioxide flux densities are likely to be characteristic of the forest for all similar temperature and soil moisture conditions.

\section{Resistances to Heat and Water Vapor Transport}

There were problems in determining the aerodynamic resistance using the wind profile. The wind measurement system was found to have "cross talk" between the measurement levels. Many efforts were made to reduce this problem but nont were fully successful. The "crosstalk" was 1 arge enough that the measurements should not be expected to be better than $10 \%$ of the measurement value. This is not adequate to make parameter estimates from the wind profile.

Instead, the equations presented above were used to estimate the value of friction velocity for each anemometer level. The value of the zero plane displacement was determined from the literature (Thom et al. 1975, Jarvis et al. 1976). Then the friction velocity and aerodynamic resistance was calculated for each level of wind measurement within a reasonable range of roughness lengths. It was found that a value of roughness length could be identified in which the friction velocity did not change very much in the upper three levels during daylight measurement periods. The roughness height was varied to determine its effect on the calculated friction velocity. It was found by trial and error that a value of 0.5 meters provided the most consistent value of friction velocity for the upper three levels. The aerodynamic resistances calculated from the friction velocity found by this method agree with others measured over forests (Jarvis et al. 1976). 
The climatological resistance was calculated as shown in Equation (11). The climatological resistance is the calculated value of the latent heat resistance if the entire net radiation was used for evaporation, and the gradient for transport was the vapor density deficit. The vapor density deficit is the difference between the saturation and actual air water vapor density.

The canopy resistance was calculated using Equation (10). Figure 7 illustrates the results for the daylight periods beginning on July 1. Almost all measurement periods show the same trend, a rapid decrease in resistance in the morning to a minimum value in the late morning or early afternoon, followed by a gradual increase through the afternoon with a rapid increase to very high values just before dark.

\section{Estimation of Annual Carbon Dioxide Exchange from Climatological Data}

The estimation of the annual flux density is basically an interpolation problem where the flux density must be estimated for the days between the days in which measurements were taken. In some cases this may also include extrapolation when the environmental conditions which control the flux density are outside those experienced during the measurement periods. The success of the interpolation will depend on developing an adequate model of the processes controlling the flux and having adequate measurements of the controlling environmental factors during the periods to be estimated. Ideally, the environmental data base would be easily available for a large number of locations, such as the U.S. National Weather Service's Daily Climatological Observations. However, it may be necessary to supplement this data base with local environmental observations, such as solar radiation or soil moisture. 


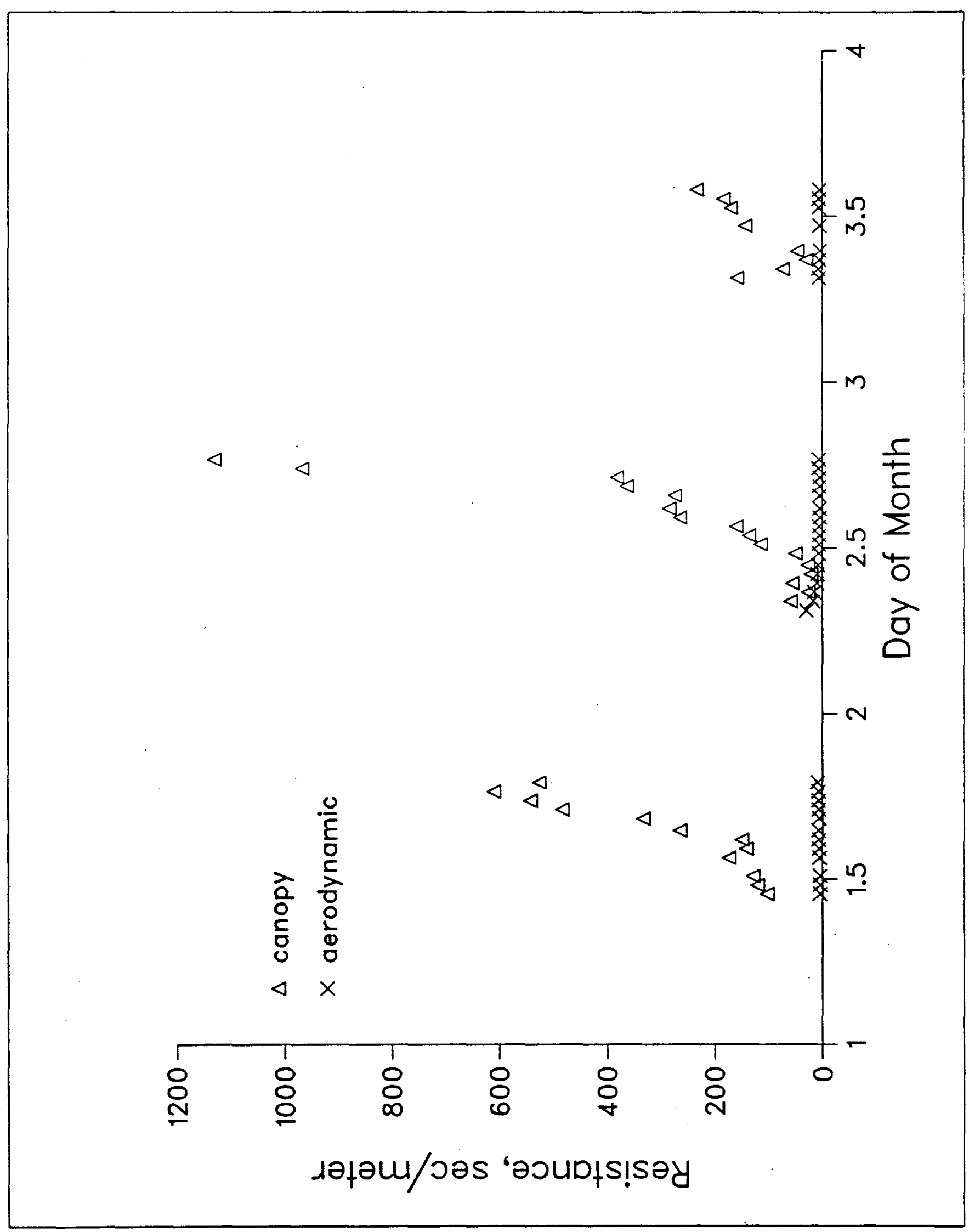


In this paper the estimate of carbon dioxide exchange is made by developing a set of 1 inear equations to estimate the transfer resistances for water vapor from climatological data. Then a relationship is developed between the transfer resistances and the climatological data to estimate the carbon dioxide exchange. The successful application of linear equations, and standard statistical techniques to develop the relationships, depends on understanding enough about the mechanisms which control the resistances to chose the correct set of independent variables. It is also usually necessary to know enough about the form of the relationships to perform correct transformations on the data where necessary. Murphy et al. 1981, found that canopy resistance could be predicted from measured values of air temperature ( $T$ ) water vapor density, and solar radiation (S) if the data were transformed by 1) dividing the canopy resistance by the leaf area to get an average leaf resistance $\left.\left(h_{1}\right), 2\right)$ inverting the leaf resistance to get a leaf conductance, 3 ) scaling the leaf resistance by maximum $\left(h_{m x}\right)$ and minimum ( $h_{m n}$ ) values from chamber experiments (12), and 4) expressing the humidity effect as a vapor density deficit (dr). The final form of the equation was

$$
\left(h_{1}-h_{m n}\right) /\left(h_{m x}-h_{m n}\right)=a_{1} S+a_{2} T+a_{3} d r
$$

Multiple linear regression procedures (SAS 1979) were used to fit an equation of this form which included solar radiation, temperature, water vapor density deficit, soil water tension, and air carbon dioxide concentration as independent variables. The resulting coefficients are shown in Table 3 . A11 of the variables were statistically significant 
at the 0.99 level except air carbon dioxide concentration. However, soil water tension was, unexpectedly, positively correlated with conductance which was not expected. A closer look at the results revealed that the addition of soil water tension to the regression had a very small change on the squared regression coefficient $(0.724$ for the three parameter model versus 0.743 for the four parameter model) and thus on the predictive capability of the model. Therefore, the three parameter model was judged the best model.

As (Jarvis et a1. 1976) have pointed out, the modeling of carbon dioxide exchange (net photosynthesis, $P_{n}$ ) from a "first principles" approach of determining the internal sink/source relationships has been difficult. They present a nonlinear empirical model where the independent variables are solar radiation and vapor pressure deficit. It is likely that most of the effect of vapor pressure deficit is an effect on the canopy resistance in the diffusion path for carbon dioxide. Therefore, a model including leaf conductance and solar radiation should apply equally well. The form used was

$$
\left(P_{n}+R\right) / P_{m x}=a_{1} S+a_{2} h_{1}
$$

The maximum gross photosynthesis $\left(P_{m x}\right)$ is an arbitrarily high value that is not likely to be exceeded $\left(15 \mathrm{mgm} / \mathrm{m}^{2} / \mathrm{s}\right)$.

The respiration of the stand ( $R$ ) includes both canopy respiration and soil respiration as determined above. It was extrapolated to daytime conditions by assuming a $Q_{10}$ of 2.2 for temperature (Figure 6). This value is close to the value found by (Kinerson 1975). Kinerson's analysis indicates an increase in the respiration during the growing 
season. The data does not exist to estimate the magnitude of the. change in seasonal respiration due to growth in this study. However, when the data in Figure 6 is used as the basis for estimating respiration, the seasonal effect is, to some extent, taken into account because the season of the year and the temperature are correlated. The low temperature data points are for periods of low growth and the high temperature data points are for periods of high growth. Since this is not always the case for all periods of the year, the estimate of respiration using this equation may be low during cool spring periods when the growth rate is high, or high during the mid-summer when temperatures are high but growth is 1 imited by water stress.

Equation (15) was found to fit the experimental data quite well with a squared regression coefficient $\left(R^{2}\right)$ of 0.805 . However, calculations of carbon dioxide exchange were higher than could reasonably be expected. Chamber data collected (Higgenbotham 1974) on loblolly pine suggest that carbon dioxide exchange is very low at temperatures near zero degrees celcius. An equation that has this characteristic is:

$$
\left(P_{n}+R\right) / P_{m x}=b_{1} S T+b_{2} h_{1} T
$$

The $R^{2}$ for this equation was 0.806 . Therefore, the fit to the data, which were collected in the summer and fall, is as good as in Equation (15) and Equation (16) has the low temperature response suggested by Higgenbotham's data. The linear estimates of the regression parameters are shown in Table 3 . 
The annual carbon dioxide exchange was calculated using the average daytime air temperature, water vapor density, and wind speed from the National Weather Service Station at Bush Field, near Augusta, Georgia. The daily solar radiation was estimated by the technique of (Satterlund and Means 1978) using locally derived fitting constants.

The net carbon dioxide exchange is estimated to be 10.5 metric tons per hectare. Figure 8 shows the monthly values of carbon dioxide flux density. The evapotranspiration is also shown, as an indicator of the relative climatic conditions. The trend in evapotranspiration is as expected; high during the late spring, summer, and early fall, and low during the winter. The peak monthly carbon dioxide flux density corresponds to the peak water use. However, the carbon dioxide flux density decreases in the summer and then increases again in the fall. In the moderate climate of this area it appears that carbon dioxide uptake by the stand is still high in the late fall. Measurements taken in early November show peak carbon dioxide uptake almost as high as during the summer. Thus it appears that, even though the needle initiation stops in late summer, and branch and needle elongation by early fall, the trees continue to accumulate carbon compounds at a fairly high rate in all but two or three months of the year.

\section{Annual Estimate of Biomass Accumulation}

Table 4 shows the coefficients, standard deviation, and regression coefficient squared for the equations used to calculate the biomass of the pine plantation. Table 5 shows the average value of stand DBH, 


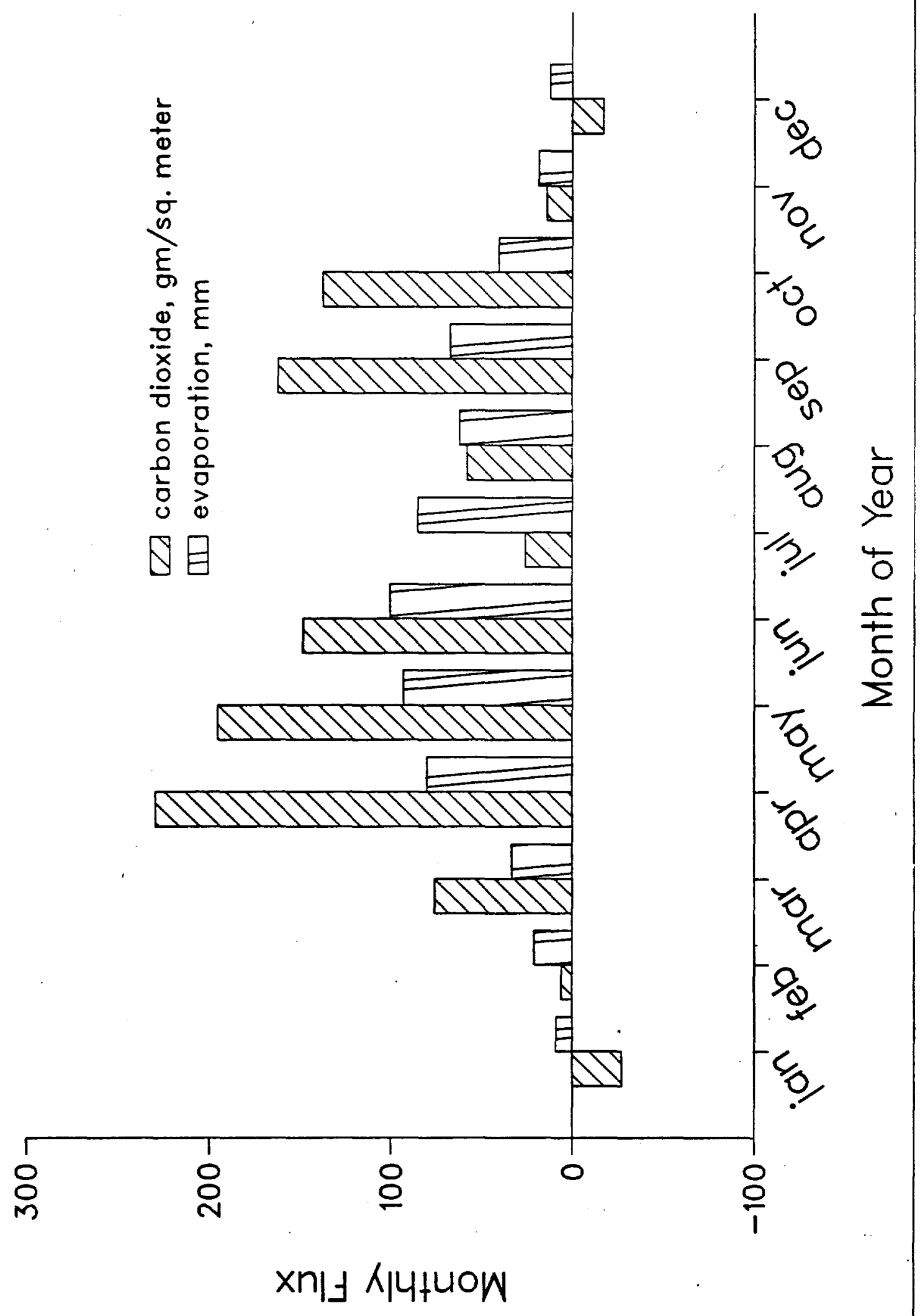


height, stocking, and the resulting biomass by tree component. The difference in mass between the winter of 1980 , and the winter of 1981 is the growth during ther 1980 growing season. The value of 4.5 metric tons per hectare agrees with the growth of similar stands reported by (Nemeth 1972) and results in an efficiency of conversion of 0.43 $(4.5 \div 10.5)$.

\section{Discussion and Conclusions}

The efficiency of conversion of carbon dioxide to biomass can be calculated using the carbon dioxide exchange extrapolated over the year and the growth estimates from the biomass measurements. The efficiency of conversion for this pine plantation is 0.43. Chung and Barnes, 1977 show that the expected efficiency for forest trees is in the range of 0.44 to 0.55 , where the average number for most tree species is likely to be nearer 0.55 than 0.44 . Thus the carbon dioxide exchange calculated by the model appears to be about $25 \%$ greater than needed to accumulate the estimated biomass. Considering the uncertainties in both the biomass and carbon dioxide measurements, this is good agreement .

Therefore, the measurement of carbon dioxide uptake and its interpolation for longer periods, by the model presented above, will provide a reasonable estimate of carbon dioxide exchange. While the carbon dioxide exchange measured by these methods may never provide practical estimates of long-term biomass accumulation, they do provide a means of understanding the dynamics of annual biomass production in situations 
that are difficult to follow by measuring biomass accumulation directly. In the case of the pine plantation studied here. the continuation of carbon accumulatino into the late fall is not readily apparent from observation of the growth of the trees. However, the carbon dioxide exchange experiment clearly shows a net uptake of carbon dioxide as late as November.

This study also supports the estimation of long-term carbon dioxide exchange by measurement of biomass accumulation. It is very difficult to maintain gas exchange experiments for periods of more than a few weeks. Therefore measurements over the life of a forest are nearly impossible. However, the close correspondence between carbon dioxide exchange and biomass accumulation provides a simple means of using a great deal of existing forest yield data to estimate the role of forests in the global carbon cycle. 


\section{References}

Bowen, I. S., 1926. The ratio of heat losses by conduction and by evaporation from any water surface. Phys. Rev. 27, 779 .

Businger, J. A., Wyngaard, J. C., Isumi, Y., and Bradley, E. F., 1971. Flux-profile relationships in atmospheric surface layer. J. Atmos. Sci. 28 .

Chung, H. and Barnes, R. L., 1977. Photosynthate allocation in Pinus Taeda L. Can. J. For. Res. 7: pp. 106-111.

Droppo, J. G., 1978. Revised method of computing energy balances over vegetation canopies. in proc. 5th National Conference on Fire and Forest Meteorology. American Meteorology Soc., Boston, MA, 19.

Hicks, B. B. and Wesely, M. L., 1980. Turbulent transfer processes to a surface and interaction with vegetation. Atmospheric Sulfur Deposition, D. S. Shriner, C. R. Richmond, and S. E. Lindberg, Ed. 199

Higginbotham, K. O., 1974. The influence of canopy position and the age of leaf tissue on growth and photosynthesis in loblolly pine. Ph. D. Dissertation Duke University, Durham, NC, 248 pp.

Jarvis, P. G., James, G. B., and Landsburg, J. J., 1976. Coniferous Forest, Vegetation and the Atmosphere, Vo1. 2, J. L. Monteith, de. Academic Press, London, p. 171.

Keeling, C. D., Bacastow, R. B., Bainbridge, A. E., Ekdahl, C. A., Jr., Guenter, P. R., Waterman, L. S., and Chin, J. G. S., 1976. Atmospheric carbon dioxide variations at Mauna Loa Observatory, Hawaii. Tellus 28,538 . 
Kinerson, R. S:, 1975. Relationships between plant surface and respiration in loblolly pine. J. Appl. Ecol. 12, 963.

Lettau, H. H., 1979. Wind and temperature profile prediction for diabatic surface layers including strong inversion cases. BoundaryLayer Meteorology 17, 443.

Monteith, J. L., 1965. Evaporation and environment. Symp. Soc. Exp. Biol. 19, 205.

Murphy, C. E., Jr., Schubert, J. F., and Dexter, A. H., 1981. The energy and mass exchange characteristics of a loblolly pine plantation. J. Appl. Ecol. 18, pp. 271-281.

Nemeth, J. C., 1972. Dry matter production and site factors in young loblolly (Pinus taeda L.) and slash pine (Pinus elliottii Engelm.) plantations, Ph. D. Dissertation, North Carolina State University, Raleigh, NC, 95 pp.

Paulson, C. A., 1970. The mathematical representation of wind speed and temperature profiles in the unstable atmospheric surface layer, J. Appl. Meteorol. 9, 857 .

Penman, H. L., 1948. Natural evaporation from open water, bare soil and grass. Proc. Roy. Soc. London (A) 193, 120.

Ralston, C. W., 1974. Annual primary productivity in a loblolly pine plantation, IUFRO Biomass Studies, H. E. Young, Ed., University of Maine, Orono, 532 pp.

Satterlund, D. R. and Means, J. E., 1978. Estimating solar radiation under variable cloud conditions, Forest Sci. 24, pp. 363-373. 
SAS User's Guide., 1979. SAS Institute Inc., Raleigh, NC, 494 pp.

Sinclair, T. R., Allen, L. H., Jr., and Lemon, E. R., 1975. An analysis of errors in the calculation of energy flux densities above vegetation by a Bowen-ratio profile method. Boundary-Layer Meteorology, 8, 129 .

Sinclair, T. R., Murphy, C. E., Jr., and Knoerr, R. R., 1976.

Development and evaluation of simplified models for simulating canopy photosynthesis and transpiration. J. App1. Ecol. 13, 813.

Stewart, J. B. and Thom, A. S., 1973. Energy budgets in pine forest. Quart. J. R. Met. Soc. 99, 154.

Thom, A. S., 1975. Momentum, mass and heat exchange of plant communities. Vegetation and the atmosphere, J. L. Monteith, Ed. Academic Press, London, p. 57.

Thom, A. S., Stewart, J. B., Oliver, H. R., and Gash, J. H. C., 1975. Comparison of aerodynamic and energy budget estimates of fluxes over a pine forest. Ouart. J. R. Met. Soc. 101, pp. 93-105. Warhaft, Z., 1976. Heat and moisture flux in the stratified boundary layer. Quart. J. R. Met. Soc., 102, 703.

Webb, E. R., Pearman, G. I., and Leuning, R., 1980. Correction of flux measurements for density effects due to heat and water vapor transfer. Quart. J. R. Met. Soc. 106, 85 .

van Wijk, W. R, and de Vries, D. A., 1966. Periodic temperature variations in a homogeneous soil. Physics of Plant Environment W. R. van Wijk, Ed., North-Holland Pub. Co., Amsterdam, p. 103. Woodwell, G. M., Whittaker, R. H., Reiners, W. A., Likens, G. E., Delwiche, C. C., and Botkin, D. B., 1978. The biota and the world carbon budget., Science 199, 141 . 


\section{APPENDIX A}

\section{EQUIPMENT}

Inst rument

Infrared gas

Dewpoint hygrometer

Anemometer

Solar radiometer

Net radiometer

Calculator-controller

Clock

Digital voltmeter

Relay actuator

Scanner

Magnetic tape
Manufacturer, Model

Easterline Angus, NDIR 743

P.0. Box 2400

Indianapolis, ID

$E G \& G, 880$

Environmental Equipment Div. 151 Bear Hill Rd.

Waltham, MA 02254

C. F. Casella, Sensitive Cup Regent House, Britainia Walk

London N. 1

The Epply Laboratory, Inc., Precision Spectral

Scientific Instruments

Newport, RI 02840

Swissteco Pty. Ltd., 622

26 Miami St.

East Hawthorn, Victoria 3123

Australia

Hewlett-Packard, $9821 \mathrm{~A}$

1601 California Ave.

Palo Alto, CA 94304

Hewlett-Packard, 59309A

Hewlett-Packard, 3490A

Hewlett-Packard, 59306A

Hewlett-Packard

Kennedy, 1707-9CR

1600 Shamrock Ave.

Monrovia, CA 91016 
Table 1

Annual Variation in Needle Surface Area

$\begin{array}{lcccccc}\text { Date Sampled } & 3 / 19 / 80 & 4 / 28 / 80 & 6 / 25 / 80 & 8 / 12 / 80 & 9 / 23 / 80 & 12 / \\ \text { Area Index* } & 3.3 & 4.4 & 4.7 & 2.1 & 3.1 & 3.7 \\ \text { * Area based on sum of all surfaces. }\end{array}$




\section{Table 2}

Soil Thermal Conductivity Estimated from Thermocouple and Soil Moisture Data

\begin{tabular}{|c|c|c|c|c|c|}
\hline Date & $\begin{array}{l}\text { Plot Soil } \\
\text { No. }\end{array}$ & $\begin{array}{l}\text { Moisture, } \\
\mathrm{v} / \mathrm{v}\end{array}$ & $\begin{array}{l}\text { Damp Depth, } \\
\mathrm{cm}\end{array}$ & $\begin{array}{l}\text { Heat Capacity, } \\
\mathrm{cal} / \mathrm{cm}^{3} /{ }^{\circ} \mathrm{C}\end{array}$ & $\begin{array}{l}\text { Conductivity, } \\
\mathrm{ca} 1 / \mathrm{cm} / \mathrm{s} /{ }^{\circ} \mathrm{C}\end{array}$ \\
\hline \multirow[t]{2}{*}{$6 / 3 / 80$} & 1 & 0.19 & 15.3 & 0.48 & $6.53 \times 10^{-4}$ \\
\hline & 2 & & 22.5 & & $14.05 \times 10^{-4}$ \\
\hline \multirow[t]{2}{*}{$7 / 1 / 80$} & 1 & 0.17 & 15.2 & 0.46 & $6.13 \times 10^{-4}$ \\
\hline & 2 & & 17.3 & & $7.98 \times 10^{-4}$ \\
\hline \multirow[t]{2}{*}{$8 / 20 / 80$} & 1 & 0.12 & 18.2 & 0.41 & $7.88 \times 10^{-4}$ \\
\hline & 2 & & 22.0 & & $11.52 \times 10^{-4}$ \\
\hline \multirow[t]{2}{*}{$8 / 26 / 80$} & 1 & 0.13 & 18.6 & 0.42 & $8.44 \times 10^{-4}$ \\
\hline & 2 & & 18.1 & & $7.94 \times 10^{-4}$ \\
\hline \multirow[t]{2}{*}{$11 / 6 / 80$} & 1 & 0.22 & 18.9 & 0.51 & $10.54 \times 10^{-4}$ \\
\hline & 2 & & 18.4 & & $9.96 \times 10^{-4}$ \\
\hline Mean & & 0.17 & 18.5 & & $9.10 \times 10^{-4}$ \\
\hline Std dev & of mean & 0.02 & 0.8 & & $0.75 \times 10^{-4}$ \\
\hline
\end{tabular}


Table 3

Regression Parameter Estimates for Canopy Conductance and Carbon Dioxide Exchange

\begin{tabular}{|c|c|c|c|c|c|c|c|}
\hline $\begin{array}{l}\text { Parameter/ } \\
\text { Equation }\end{array}$ & ${ }^{\mathrm{T}_{1}} \mathrm{C}$ & $\begin{array}{l}\mathrm{S}_{2} \\
\mathrm{~W} / \mathrm{m}^{2}\end{array}$ & $\begin{array}{l}\mathrm{dr} \\
\mathrm{gm} / \mathrm{m}^{3}\end{array}$ & $\begin{array}{l}\mathrm{h}_{1} \\
\mathrm{~cm} / \mathrm{s}\end{array}$ & $S x \quad T_{1}$ & $h_{1} \times T_{1}$ & $R^{2}$ \\
\hline (14) & $0.01218 *$ & $1.110 \times 10^{-2}$ & -0.04374 & & & & 0.819 \\
\hline (15) & & $9.415 \times 10^{-5}$ & & 3.557 & & & 0.805 \\
\hline (16) & & & & & $3.162 \times 10^{-6}$ & 0.1396 & 0.807 \\
\hline
\end{tabular}

* All parameters are significant at the $99 \%$ level. 
Table 4

Regression Parameter Estimates for Mass of Tree Components

Parameter/

Tree

Component $\mathrm{DBH} \times \mathrm{HT}$ Intercept In $(\mathrm{DBH}+1)$

$[\ln (\mathrm{DBH}+1)]$

$[\ln (\mathrm{HT})]^{2}$

$R_{2}$

Need $1 e^{\star}$

2.6782

0.45

Branch

3.6619

0.96

$\ln ($ stem)

$-2.6619$

1.3968

0.11902

0.23986

0.99

* Units DBH in centimeters and HT in meters 
Table 5

Biomass and Growth Estimates, metric tons/hectare

$\underline{\text { Year }} \underline{\text { Stem* }}$ Branches Roots** Needle Total

$\begin{array}{llllll}1980 & 8.78 & 2.24 & 2.75 & 1.64 & 13.78\end{array}$

$\begin{array}{llllll}1981 & 11.52 & 3.09 & 3.65 & 1.64 & 18.26\end{array}$

$\begin{array}{llllll}\text { Growth } & 2.74 & 0.85 & 0.90 & 0.0 & 4.49\end{array}$

* Nemeth 1972

$* *$ Nemeth $1972,20 \%$ of total biomass 
Figure 1. Potential temperature at each measurement height plotted against the water vapor density and the carbon dioxide concentration.

Figure.2. Diurnal variation in temperature, water vapor density, and carbon dioxide concentration during the measurement period beginning on July 1,1980 .

Figure 3. Diurnal variation in flux densities of solar radiation, net radiation, and ground heat transfer for the measurement period beginning on July 1, 1980 .

Figure 4. Diurnal variation in the calculated flux densities of latent heat of evaporation and sensible heating of the air for the measurement period beginning on July $1,1980$.

Figure 5. Diurnal variation in the calculated flux density of carbon dioxide for the measurement period beginning on July 1,1980 .

Figure 6. Nocturnal carbon dioxide efflux for the pine forest and the surface of the forest floor.

Figure 7. Aerodynamic and canopy resistance for the daylight periods on July 1,2 , and 3,1980 .

Figure 8. Calculated monthly evaporation and carbon dioxide exchange of the pine forest using 1980 climatic data. 